\title{
Umbilicated Neoplasm on the Chest
}

Bo Li, MD; Xiangqian Li, MD; Manuel Valdebran, MD; Xi Chen, MD; Xianghe Wang, MD; Xueyan Yao, MD; Cheng Zhou, MD
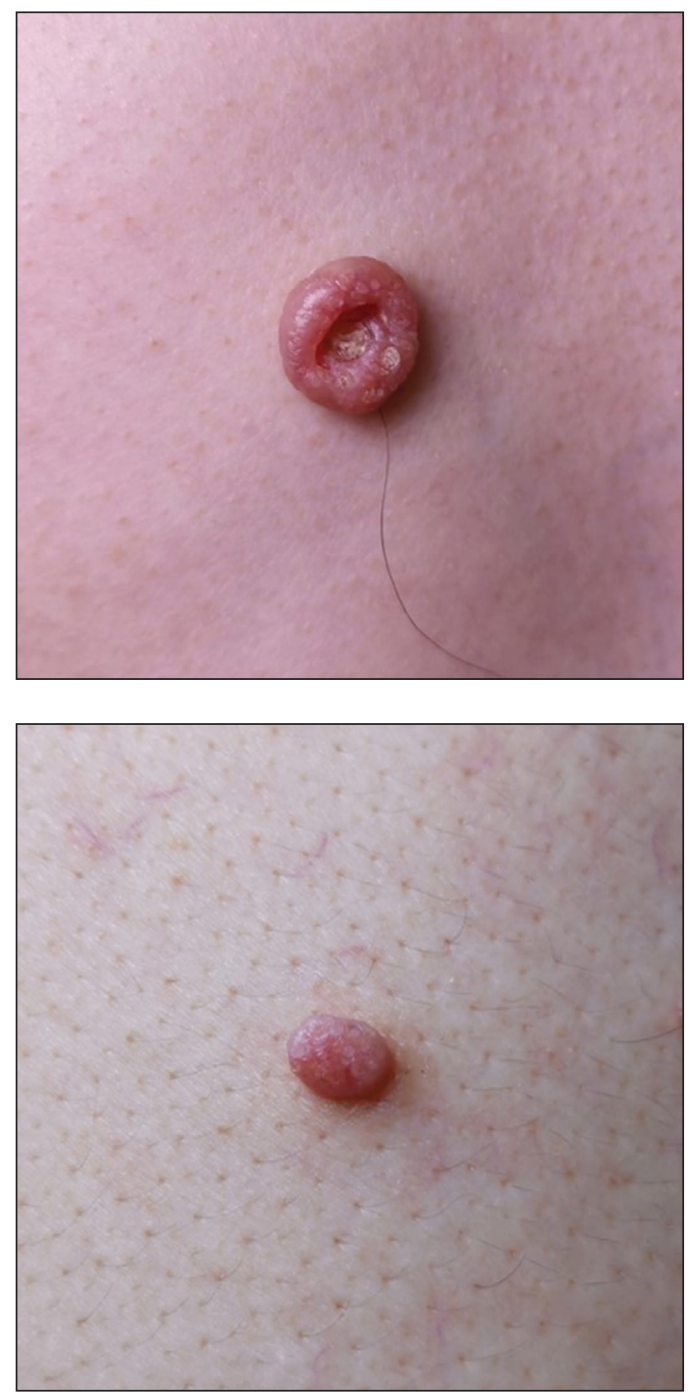

A 49-year-old man presented with a slow-growing mass on the chest of 1 year's duration. The neoplasm started as a small papule that gradually increased in size. The patient denied pain, itching, bleeding, or discharge. He had a history of end-stage renal disease with a kidney transplant 8 years prior. His medication history included long-term use of oral tacrolimus, mycophenolate mofetil, and prednisone. Physical examination revealed a yellowish red, exogenous, pedunculated neoplasm on the right side of the chest measuring $1 \mathrm{~cm}$ in diameter with an umbilicated center and keratotic material (top). There were 2 more yellowish red papules on the left side of the chest measuring $0.5 \mathrm{~cm}$ in diameter without an umbilicated center (bottom). Dermoscopy and a biopsy were performed.

\section{WHAT'S YOUR DIAGNOSIS?}
a. basal cell carcinoma
b. keratoacanthoma
c. molluscum contagiosum
d. squamous cell carcinoma
e. xanthomatosis 


\section{THE DIAGNOSIS:}

\section{Molluscum Contagiosum}

$\mathrm{D}$ ermoscopy showed polylobular, whitish yellow, amorphous structures at the center of the lesion surrounded by a crown of vessels (Figure 1). Histopathology revealed hyperplastic crateriform lesions containing large eosinophilic intracytoplasmic inclusion bodies within keratinocytes (Figure 2). At follow-up 2 weeks after the biopsy, the patient presented with approximately 20 more reddish papules of varying sizes on the abdomen and back that presented as dome-shaped
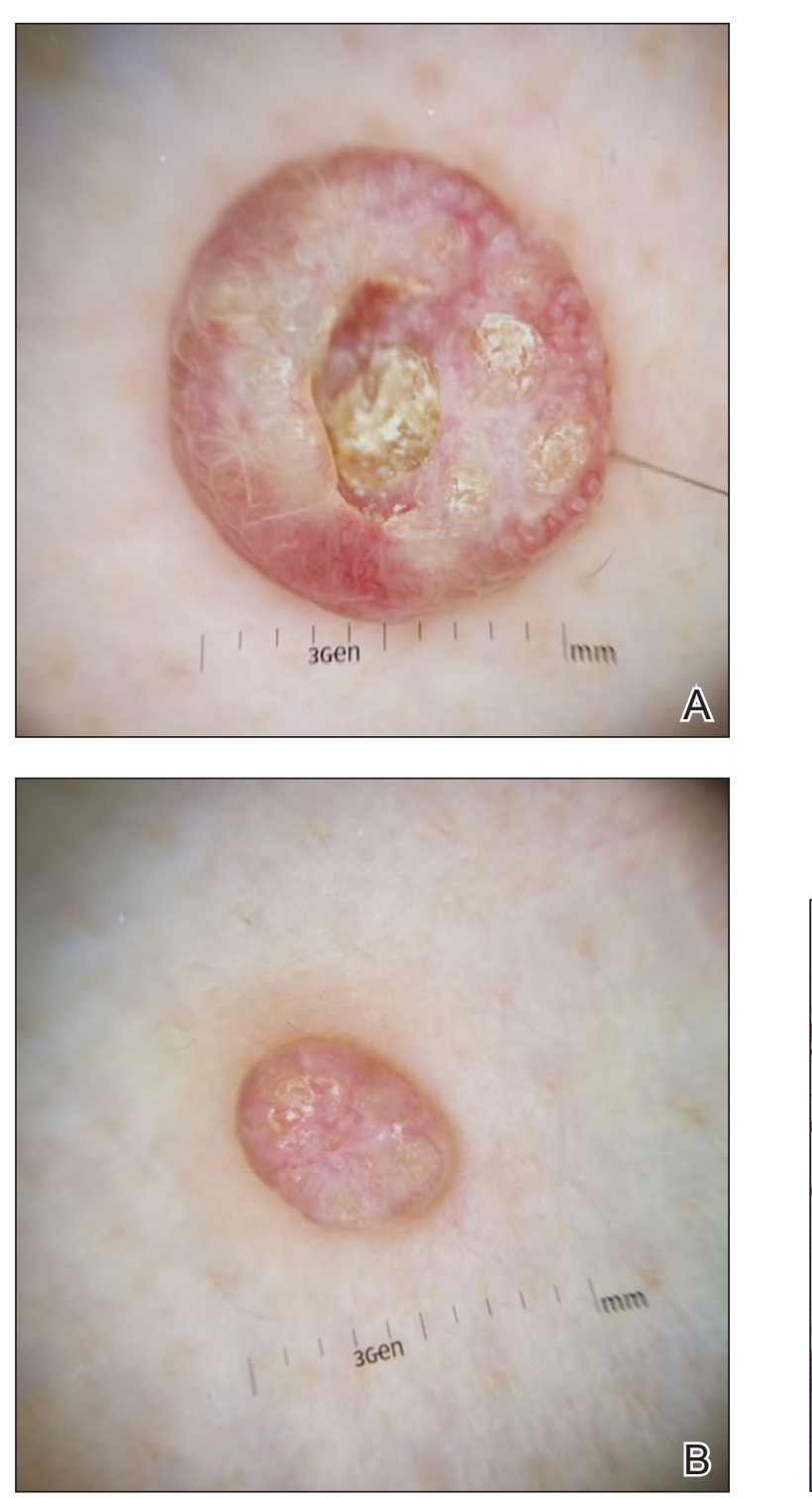

FIGURE 1. A and B, Dermoscopy revealed a crown of vessels at the periphery of the lesion with polylobular, whitish yellow, amorphous structures in the center (original magnifications $\times 10$ ). papules and had a typical umbilicated center. The clinical manifestations, dermoscopy, and pathology findings were consistent with molluscum contagiosum (MC).

Molluscum contagiosum was first described in 1814 . It is a benign cutaneous infectious disease caused by a double-stranded DNA virus of the poxvirus family. Molluscum contagiosum lesions usually manifest clinically as dome-shaped, flesh-colored or translucent, umbilicated papules measuring 1 to $5 \mathrm{~mm}$ in diameter that are commonly distributed over the face, trunk, and extremities and usually are self-limiting. ${ }^{1}$

Giant MC is rare and can be seen either in patients on immunosuppressive therapy or in those with diseases that can cause immunosuppression, such as human immunodeficiency virus, leukemia, atopic dermatitis, Wiskott-Aldrich syndrome, and sarcoidosis. In these instances, $\mathrm{MC}$ often is greater than $1 \mathrm{~cm}$ in diameter. Atypical variants may have an eczematous presentation or a lesion with secondary abscess formation and also can be spread widely over the body. ${ }^{2}$ Due to these atypical appearances and large dimensions in immunocompromised patients, other dermatologic diseases should be considered in the differential diagnosis, such as basal cell carcinoma, keratoacanthoma, squamous cell carcinoma, cutaneous horn, cutaneous cryptococcosis, histoplasmosis, and xanthomatosis. ${ }^{3}$

In our patient, the differential diagnosis included keratoacanthoma, which may present as a solitary, discrete, round to oval, flesh-colored, umbilicated nodule with a central keratin-filled crater and has a rapid clinical evolution, usually regressing within 4 to 6 months.

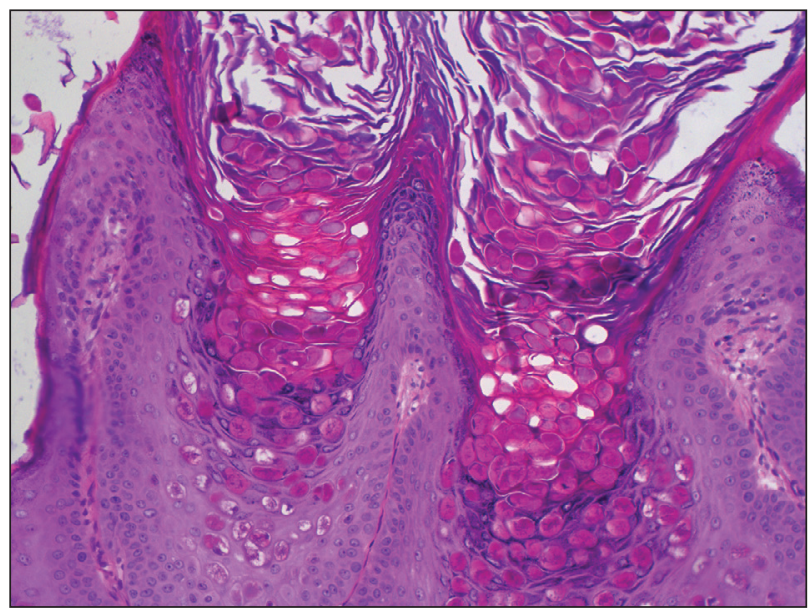

FIGURE 2. Histopathology revealed hyperplastic lesions of the epidermis with a central crater and eosinophilic inclusion bodies within the keratinocytes $(\mathrm{H} \& \mathrm{E}$, original magnification $\times 200)$. 
Squamous cell carcinoma may appear as scaly red patches, open sores, warts, or elevated growths with a central depression and may crust or bleed. Basal cell carcinoma typically may appear as a dome-shaped skin nodule with visible blood vessels or sometimes presents as a red patch similar to eczema. Xanthomatosis often appears as yellow to orange, mostly asymptomatic, supple patches or plaques, usually with sharp and distinctive edges.

Ancillary diagnostic modalities such as dermoscopy may be used to improve diagnostic accuracy. The bestknown capillaroscopic feature of $\mathrm{MC}$ is the peripheral crown of vessels in a radial distribution. A study of $258 \mathrm{MC}$ lesions highlighted that crown and crown plus radial arrangements are the most common vascular structure patterns under dermoscopy. In addition, polylobular amorphous white structures in the center of the lesions tend to be a feature of larger MC papules. ${ }^{4}$ Histologically, MC shows lobulated crateriform lesions, thickening of the epidermis into the dermis, and the typical appearance of large eosinophilic intracytoplasmic inclusion bodies within keratinocytes. ${ }^{5}$

There are several treatment options available for MC. Common modalities include liquid nitrogen cryospray, curettage, and electrocauterization. In immunocompromised patients, MC lesions usually are resistant to ordinary therapy. The efficacy of topical agents such as imiquimod, which can induce high levels of IFN- $\alpha$ and other cytokines, has been demonstrated in these patients. ${ }^{6}$ Cidofovir, a nucleoside analog that has potent antiviral properties, also can be included as a therapeutic option. ${ }^{3}$ Our patient's largest MC lesion was treated with surgical excision, the 2 large lesions on the left side of the chest with cryotherapy, and the other small lesions with curettage.

\section{REFERENCES}

1. Hanson D, Diven DG. Molluscum contagiosum. Dermatol Online J. 2003;9:2.

2. Singh S, Swain M, Shukla S, et al. An unusual presentation of giant molluscum contagiosum diagnosed on cytology. Diagn Cytopathol. 2018;46:794-796

3. Mansur AT, Goktay F, Gunduz S, et al. Multiple giant molluscum contagiosum in a renal transplant recipient. Transpl Infect Dis. 2004;6:120-123.

4. $\mathrm{Ku} \mathrm{SH}, \mathrm{Cho}$ EB, Park EJ, et al. Dermoscopic features of molluscum contagiosum based on white structures and their correlation with histopathological findings. Clin Exp Dermatol. 2015;40:208-210.

5. Trčko K, Hošnjak L, Kušar B, et al. Clinical, histopathological, and virological evaluation of 203 patients with a clinical diagnosis of molluscum contagiosum [published online November 12, 2018]. Open Forum Infect Dis. 2018;5.

6. Gardner LS, Ormond PJ. Treatment of multiple giant molluscum contagiosum in a renal transplant patient with imiquimod $5 \%$ cream. Clin Exp Dermatol. 2010;31:452-453. 